\section{Vitiligo, morphea and Sjögren's syndrome: a case study}

\author{
Sema Yilmaz,' Kadriye Akar Cimen² \\ 'Division of Rheumatology, Selcuklu \\ Faculty of Medicine, Selcuk University, \\ Konya; ${ }^{2}$ Division of Dermatology, Konya \\ Education and Research Hospital, Konya, \\ Turkey
}

\section{Introduction}

Sjögren's syndrome, vitiligo, and morphea are three distinct autoimmune diseases of unknown etiology. The existence of autoantibodies support an autoimmune hypothesis of these diseases. ${ }^{1,2,3}$

\section{Case Report}

A 56-year-old woman was admitted to the rheumatology clinic with symptoms of burning and the feeling of grit or sand in her eyes. She also had dryness of the mouth, giving rise to difficulties with speech and swallowing food. The presence of anti-Ro/SSA and anti-La/SSB autoantibodies, and grade 4 chronic lymphocytic sialadenitis on biopsy of the salivary gland, together with the clinical findings revealed Sjögren's syndrome. The patient was referred to the dermatology clinic because of widespread depigmentation in the middle of her back (Figure 1). Following the dermatological examination, the patient was considered to have vitiligo. With the help of Wood's light examination, the diagnosis was confirmed. Another remarkable dermatological finding was violaceous-colored, slightly depressed and atrophic oval plaques of variable size $(10 \times 10$ $\mathrm{cm}$ to $7 \mathrm{x} 8 \mathrm{~cm})$ on the abdominal and gluteal regions (Figure 2). Histopathological examination of these lesions demonstrated morphea. The patient was unaware of these dermatological conditions.

In her past history, the patient had received radioactive iodine therapy for an adenoma of the thyroid gland eight years ago. In the family history, her daughter had been diagnosed with rheumatoid arthritis. Systemic examination of the patient was unremarkable. There was no systemic involvement associated with the morphea and Sjögren's syndrome. Laboratory findings for a complete blood cell count, vitamin B12 levels, biochemical analysis, and urinalysis were normal. However, on admission abnormal laboratory findings included: erythrocyte sedimentation rate, 30 $\mathrm{mm} /$ hour (normal range, 0-20 mm/hr); C-reac- tive protein, $3 \mathrm{mg} / \mathrm{L}(0-5 \mathrm{mg} / \mathrm{L})$; rheumatoid factor (RF), $604 \mathrm{IU} / \mathrm{ml}(0-15 \mathrm{IU} / \mathrm{mL})$; and antinuclear antibody (ANA), 1/320 granular pattern. While anti-Ro/SSA and anti-La/SSB antibodies were positive, anti-double-stranded DNA (anti-dsDNA), and anti-centromere antibody were negative. A biopsy of the salivary gland revealed grade 4 chronic lymphocytic sialadenitis based on the Chilsom classification. Schirmer's tear test was used for the evaluation of tear secretion by the lacrimal glands. There was wetting of less than $5 \mathrm{~mm}$ per 5 min. This demonstrated a strong indication of diminished secretion.

Autoimmune etiology is thought to play a role in these diseases. Sjögren's syndrome is an autoimmune disorder with a higher female incidence, distinctive human leukocyte antigen (HLA) associations, familial clustering with other autoimmune processes, and the presence of autoantibodies, such as antiRo/SSA and anti-La/SSB antibodies. ${ }^{4}$ The association of vitiligo with autoimmune diseases has suggested an immunological basis for vitiligo. Involvement of humoral immunity was first demonstrated by the finding of circulating antibodies directed to melanocytes. The vitiligo antibodies are attracted predominantly to various melanocyte antigens, including tyrosinase, tyrosinase-related protein 1 , and tyrosi-
Correspondence: Sema Yilmaz, Vatan cad Devrim sitesi B/Blok No: 25/4, 42040 Selcuklu, Konya, Turkey. E-mail: drsemayilmaz@hotmail.com/ drsemayilmaznew@gmail.com

Received for publication: 12 June 2009. Revision received: 18 August 2009.

Accepted for publication: 18 August 2009.

This work is licensed under a Creative Commons Attribution 3.0 License (by-nc 3.0)

(C) Copyright S. Yilmaz et al., 2009

Licensee PAGEPress, Italy

Rheumatology Reports 2009; 1:e7

doi:10.4081/rr.2009.e7

nase-related protein 2 . Recently, autoantibodies to a transcription factor called S0X10 have been found in vitiligo related to polyglandular dysfunction. ${ }^{5}$ Some studies have indicated an association of autoimmune diseases with morphea. In addition to positive titers of ANA, antidsDNA, and anti-scleroderma (-Scl) 70 antibodies, increased RF levels suggest that an immunological process occurring in morphea. ${ }^{6,7}$

Although Sjögren's syndrome, vitiligo, and morphea are autoimmune diseases, they are seen together rarely. A few studies have report-
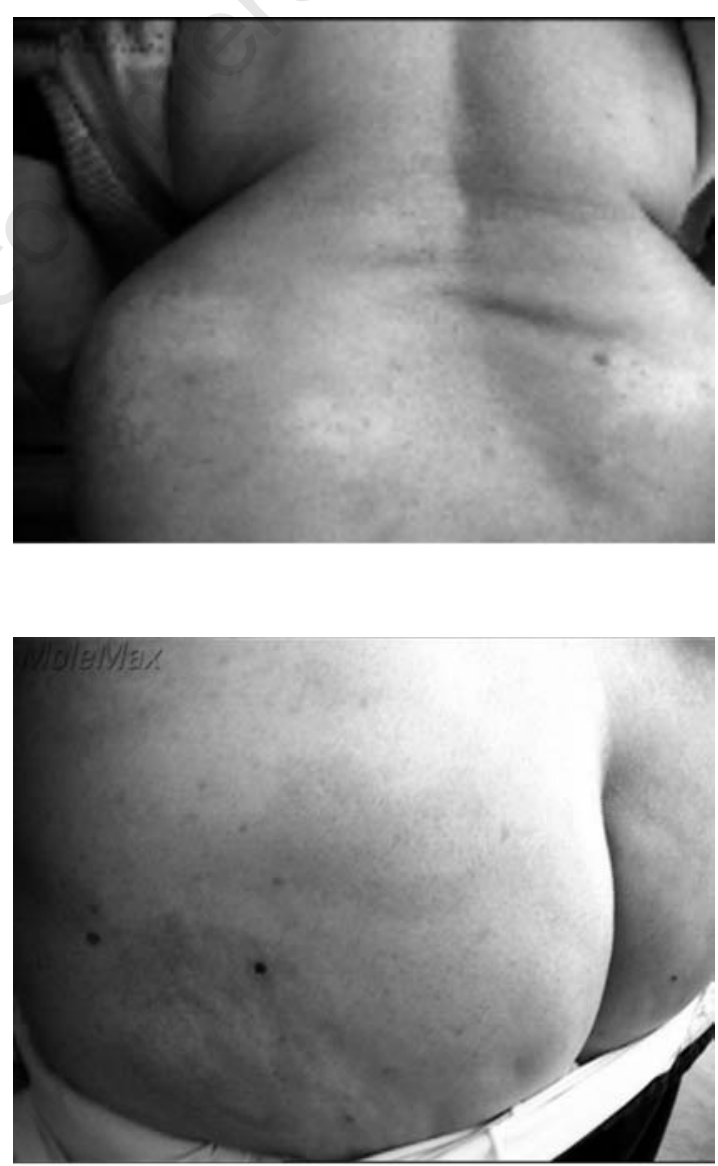

Figure 1. Vitiligo localized in the lumbar region.
Figure 2. Morphea localized in the gluteal region. 
ed an association between morphea and vitiligo to date. ${ }^{8,9}$ There is one reported case of alopecia areata, lichen planus, and onychodistrophy in a patient with vitiligo and morphea. ${ }^{10}$ Among other reported cases are Hashimoto thyroiditis with vitiligo and morphea, ${ }^{1}$ as well as alopecia areata and ulcerative colitis with vitiligo and scleroderma. ${ }^{11}$ There is no data in the literature to evaluate the coincidental occurrence of these diseases; the associations between vitiligo, morphea, and other autoimmune diseases were revealed by case studies.

To our knowledge, there is no reported case of an association between vitiligo, morphea, and Sjögren's syndrome. The existence of an autoimmune disease makes people prone to other autoimmune diseases. Because of this condition, the patients with an autoimmune disease should be followed carefully.

\section{References}

1. Dervis E, Acbay 0, Barut G, et al. Association of vitiligo, morphea, and Hashimoto's thyroiditis. Int $\mathbf{J}$ Dermatol 2004;43:235-6.

2. Kemp EH, Gavalas NG, Gawkrodger DJ, et al. Autoantibody responses to melanocytes in the depigmenting skin disease vitiligo. Autoimmun Rev 2007;6:138-42.

3. Salomonsson S, Jonsson MV, Skarstein K, et al. Cellular basis of ectopic germinal center formation and autoantibody production in the target organ of patients with Sjögren's syndrome. Arthritis Rheum 2003;48:3187-201.

4. Fox RI, Liu AY. Sjögren's syndrome in dermatology. Clin Dermatol 2006;24:393-9.

5. Ortonne JP, Bahadoran P, Fitzpatrick TB, et al. Hypomelanoses and hypermelanoses. In: Freedberg IM, Eisen AZ, Wolff K, Austen KF, Goldsmith LA, Katz SI, editors. Fitzpatrick's Dermatology in General Medicine, 6th edn, New York: McGraw-
Hill, 2003;90:836-905.

6. Bernstein JE, Medenica M, Soltani K. Coexistence of localized bullous pemphigoid, morphea, and subcorneal pustulosis. Arch Dermatol 1981;117:725-7.

7. Hayakawa I, Hasegawa M, Takehara K, et al. Anti-DNA topoisomerase II alpha autoantibodies in localized scleroderma. Arthritis Rheum 2004;50:227-32.

8. Lerner AB, Sansing J. Vitiligo and linear scleroderma. Arch Dermatol 1973; 108:286-7.

9. Finkelstein E, Amichai B, Metzker A. Coexistence of vitiligo and morphea: a case report of the literature and review. J Dermatol 1995;22:351-3.

10. Brenner W, Diem E, Gschnait F. Coincidence of vitiligo, alopecia areata, onychodystrophy, localized scleroderma and lichen planus. Dermatologica 1979; 159:356-60.

11. Thompson DM, Robinson TWE, LennardJones J. Alopecia areata, vitiligo, scleroderma and ulcerative colitis. Proc R Soc Med 1974;67:1010. 